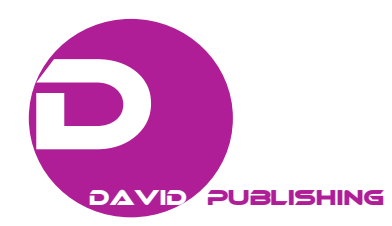

\title{
Thermal Bridges Impact on Energy Consumption in Residential Buildings Considering the Brazilian Bioclimatic Zoning
}

\author{
Eduardo Grala da Cunha ${ }^{1}$, Julye Ramalho de Freitas ${ }^{1}$, Beatriz Echenique Gioielli ${ }^{1}$, Rodrigo Karini Leitzke ${ }^{2}$ and \\ Letiane Benincá ${ }^{3}$ \\ 1. Laboratory of Comfort and Energy Efficiency, Faculty of Architecture and Urbanism, Federal University of Pelotas, Pelotas \\ 96010-020, Brazil \\ 2. Computer Science, Federal University of Pelotas, Pelotas 96010-020, Brazil \\ 3. IMED, Meridional College, Passo Fundo 99070-220, Brazil
}

\begin{abstract}
With the considerable increase in electric power consumption, searching for buildings with lower energy impact has become a crucial factor on controlling energy consumption, as well as designing buildings with high thermal comfort. Thermal bridges are weak points in buildings where the thermal resistance varies considerably between two distinct points. Depending on the situation, the existence of thermal bridges in a building can be favorable to the achievement of the expected thermal comfort and lower energy consumption. The aim of this paper is to analyze the impact of thermal bridges of reinforced concrete structure regarding to energy consumption for residential buildings in the Brazilian bioclimatic zones. The used method is characterized by computer simulations of distinct cases configured with and without thermal bridges. The results show that in most bioclimatic zones, the presence of thermal bridges in the wall composition contributes to the reduction of energy consumption for both heating and cooling, and independent of the wall's insulation level, solar absorptance is a major factor in the energy consumption levels, walls with smaller absorptance consume less and this consumption increases gradually with increasing absorptance.
\end{abstract}

Key words: Thermal bridges, energy modeling, energy efficiency, residential buildings.

\section{Introduction}

The electric energy consumption in Brazil has been growing at full speed. Today, the buildings represent $48.5 \%$ of the energy consumption, the residential sector being the largest consumer, responsible for $24.2 \%$ of those, followed by the commercial sector with $16.3 \%$ of the consumption and the public sector, $8 \%$ [1]. In a residential building, considering an average between the regions of the country, the cooling equipments are responsible for $27 \%$ of the consumption; $24 \%$ is attributed to water heating; $20 \%$ to air conditioning; $14 \%$ to lighting and $15.5 \%$ represent other equipments [2].

Corresponding author: Eduardo Grala da Cunha, professor, research fields: energy efficiency and thermal performance.
There are several variables that can influence on the consumption and efficiency of a building: climate variables, related to the place where they are inserted, architectural variables or human variables. In the architectural variables, the envelope of the building sets the starting point to check the need of heating, cooling and ventilation systems, being directly linked to factors that will contribute to the greater or less energy consumption.

The first step to promote the use of efficiency energy in buildings is the evaluation of thermo energy performance. Through this evaluation, it is possible to check if the building is meeting its main task of meeting the needs of users and whether this is effectively happening or not. A considerable part of the buildings wastes a great amount of energy in order 
to achieve environmental comfort, by not incorporating the advances of bioclimatic architecture, construction materials and appropriate techniques into their projects.

Worldwide, the concerns on energy savings and more sustainable buildings have resulted in the improvement of buildings codes in several countries since the 1970s. In 2002, the European Union published the EPBD (Energy Performance of Buildings Directive), which aims to ensure that in all member states, the buildings will be nearly-ZEB (zero-energy buildings) or NZEB, buildings with consumption close to zero. The goal is that by the end 2018, new public occupied or private buildings should have power consumption close to zero, and by the end of 2020, this rule will be valid for all new building. Therefore, each country should define its own methodologies, according to their national, regional or local conditions.

In Brazil, the discussions and concerns on energy efficiency only started having some importance after 2001, due to the crisis in the energy sector that forced the country to seek for more effective measures, along with the rationalization of electricity consumption. In the October of 2001, it was enacted the Law 10295 [3] which defines the national policies on conservation and rational use of energy in the country. On December 19, 2001, the 4059 Decree [4] came into force to regulate the Law 10295 [3], and it established the maximum levels of energy consumption or energy efficiency minimum of machines and equipment produced or marketed inside the country, as well as the buildings. In 2005, the first standards of evaluation of the thermal performance emerged in the country, the Brazilian Technical Standard, NBR (Brazilian Technical Standard) 15220 [5], which evaluates the thermal performance of buildings of social interest. In this standard, is defined the Brazilian bioclimatic zoning, which establishes the guidelines and strategies of to the eight different zones of the country. Then, in 2008, it was published the first version of the
Brazilian Technical Standard, NBR 15575 [6], which evaluates the performance of residential buildings and defines 13 aspects to be considered during the analysis of the residential building. This standard was updated in 2013 when it actually took effect. The NBR 15220 [5], has already been quite challenged in researches and academic works. Another developed research, which observed, through a process of computational simulation in naturally ventilated housing, that the limitation of the lag predicted heat in the standard do not justify, on the basis that all the walls with the thermal transmittance within the limits established feature similarity in the results of degree-hour for the Bioclimatic Zone 3 [7]. The mentioned author analyzes the values recommended by NBR 15220 [5] for social housing buildings and concludes that the standard's recommendations, especially those which limit the value of the lag of thermal walls to $4.3 \mathrm{~h}$, for the Bioclimatic Zone 2, prevent the achievement of better levels of thermal comfort in the building [8]. The results obtained through the process of computer simulation show that increasing of the thermal lag in opaque enclosures is beneficial for the elevation of these indexes. It also shows that higher solar asborptance values produce a higher percentage of thermal comfort in residential houses. Therefore, the limitation of the solar heat factor as it is given in the standard is shown to be contrary to obtaining better comfort indexes in residential houses.

The NBR 15575 [6], prior to NBR 15220 [5], already uses some different parameters for simplified building assessment. The NBR 15575 [6] uses the thermal capacity and not the thermal lag as a limiter, the same criteria of the Technical Regulation of Quality for the Level of Energy Efficiency of Residential Buildings [9], which uses it as an essential requirement. Neither of the two standards presents any consideration on thermal bridges in the thermal transmittance calculations. The existence of thermal bridges in buildings can promote increasing on heat exchanges on the envelope, because they are weak 
points, where the heat flows differently and more easily. This leads directly to an increase on energy consumption.

In the international scenery, the consequences of having thermal bridges in buildings are being considered, and there are already standards that address this issue. The Swiss Standards EN ISO 14683 [10] and EN ISO 10211 [11] determinate detailed methods for calculation of thermal bridges. The Argentinian Standards IRAM 11630 [12] and IRAM 11605 [13] determinate, respectively, the procedures for the assessment of superficial condensation risk and maximum thermal transmittance value in opaque enclosures. The German standard DIN 4108 [14] addresses issues such as protection against humidity and the possibility of mold formation, calculation methods and guidelines for construction. There is also the Portuguese Thermal Regulation [15] that presents calculation methods of simplified thermal bridges.

\subsection{Thermal Bridges}

Thermal bridge is the term that refers to all and any zone of the envelope of the building in which the thermal resistance is significantly changed in relation to the current zone.

In a research, the author says that the envelope of a building has numerous zones where there are changes in the level of the geometry of the construction elements, the properties of the materials, for example, thermal conductivity, which affects the heat flow direction and generates two-dimensional or three-dimensional heat flows. These are the zones of the envelope that constitute the so-called thermal bridges (Fig. 1) [16].

According to the standard EN ISO 12211 [11], the thermal bridges are part of the building envelope where the thermal resistance is modified by:

- A full or partial penetration of the building envelope by different thermal conductivity materials;

- A change in the thickness of the structure;
- A difference between the external and internal structures, as occurs in the connections wall/floor/ceiling.

In all these cases, the heat flow goes along the path in which the thermal resistance is weaker. This is the role of the distance between points and the thermal conductivity of the material.

Concerning the path which the heath flow passed through, the thermal bridges can be classified into three different types: three-dimensional, two-dimensional and punctual thermal bridges.

The two-dimensional thermal bridges are constituted by the connection of two or more constructive elements and characterized by a linear heat transfer coefficient $\left(\mathrm{W} / \mathrm{m}^{2} \cdot \mathrm{K}\right)$. The three-dimensional thermal bridges most of the times are the result of the union of two two-dimensional thermal bridges, for instance, the edge zone of the envelope (the intersection of two vertical and one horizontal elements). The punctual thermal bridges are those in which the three-dimensions belong all to the same order of magnitude, as for example, the vertex of the union between three flat elements (e.g., two walls and a floor).

In another study, which analyzed the impact of thermal bridges in reinforced concrete structures in the

\section{WALL MODELS SIMULATED}

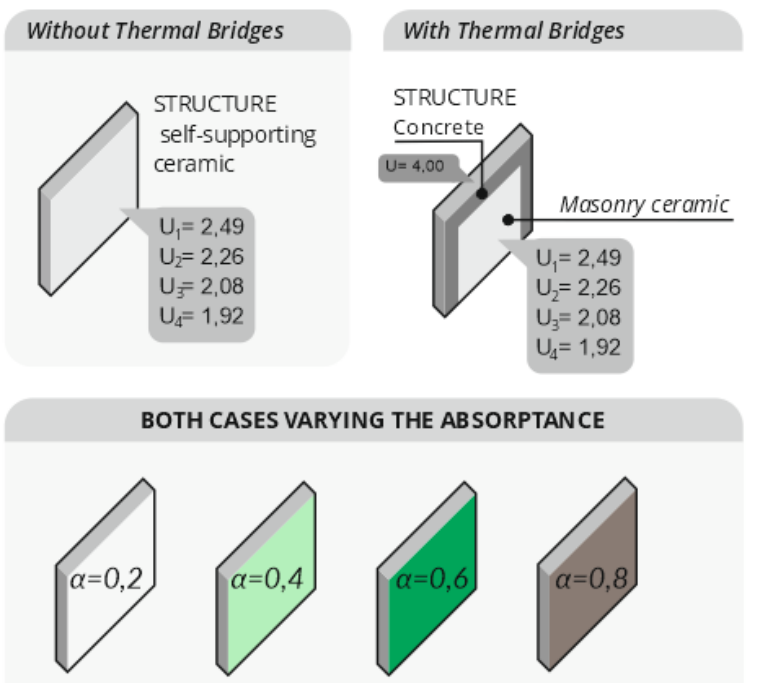

Fig. 1 Parameters for simulation. 
energy performance of hotel buildings for four Brazilian bioclimatic zones, it was verified that the thermal bridges interfere with the thermo-energetic performance of the buildings [17]. The results show that for the hotel buildings with $30 \%$ to $45 \%$ of total opening percentage, thermal bridges imply a decrease of the estimated consumption, depending on the bioclimatic zone it can reach $10 \%$. In the case of $60 \%$ of the total opening percentage, the non-consideration of the thermal bridge can represent an increase of up to $4 \%$ in the estimation of consumption depending on the climate zone in Brazil.

The study above claims that at international level, the adverse consequences of thermal bridges are recognized, and strategies for their correction have already been used. In addition to providing a path for the heat flow and increasing thermal losses of the thermal bridges, they also aggravate the possibility of the surface condensation and the formation of filamentous fungi [17]. According to researchers, the thermal bridges favor the surface condensation [18]. The Argentinian standard IRAM 11549 [19] also points out that the thermal bridge will cause increased heat flow and result in surface condensation. In the same context, another researcher states that the thermal bridges generate a decline of the temperature of surfaces that can lead to condensation surface [20].

The direct consequence of the condensation surface caused by the thermal bridges is most often the formation of mold. The humidity in the constructions according to this researcher has three distinct sources: ascending humidity, the humidity of the rain and the diffusion and convection through parts of the building [20]. The thermal bridges provide condensation of the humidity on the surfaces of the closures a result of the low surface temperature being lower than the dew point temperature.

The second part of the standard DIN 4108 [14], contrary to the edition of 1981, increased the minimum values of the resistances for walls and roofs, and kept the mold formation requirements for the first time. The new standard defined an $80 \%$ relative humidity as a condition for mold growth on interior surfaces of exterior walls. The authors of this research further state that the humidity is given as the primary condition to the formation of mold. When the surface of the wall shows humidity higher than or equal to $80 \%$ for more than $6 \mathrm{~h}$ a day, mold may grow [21]. The optimum relative humidity for mold growth is between $90 \%$ and $98 \%$. It still proves that xerophile fungi may develop with air relative humidity of $65 \%$. In regard to nutritional requirements, it has been proven that a dirty wall is already enough for mold growth. In addition to the mold, surface condensation brings up pathological problems on the surfaces contributing to the degradation of enclosures.

\subsection{Computational Simulation}

Two authors claim that "Computer simulation is one of most powerful tools of analysis in our world today-it is used to simulate everything, from games, economic growth, to engineering problems" and that “...predicting and analyzing, in advance, the future behavior of the buildings is much more efficient and economical than solving problems when the building is in use phase" [22]. Therefore, it is possible to say that simulation aims to understand and prove the efficiency of any system to improve thermal comfort to the existing environment, it is the cheapest and most efficient way to determine whether it works. This further assists in choosing a given particular solution, considering energy costs, for example.

The utilization of computational tools can occur either in the design phase as well as during the construction of the building. The easiness of manipulation of the variables involved in the construction, the low cost and optimization time, contribute even more to the use of computer simulation programs [7].

The DOE (Department of Energy) of the United States has the Energy Software Tools Directory for 
Building, where it is possible to access the 407 computer programs registered and developed in various parts of the world for energy efficiency assessments, renewable energy and sustainability in buildings. They can be accessed through this portal and provide a brief description of each.

The DOE-2.1E program, developed by the US Department of Energy for ASHRAE (American Society of Heating Refrigerating and Airconditioning Engineer), is a support tool to the standards developed by it. Such software examines the energy performance and operation cost of buildings life cycle. The creators of BLAST (Building Loads Analysis and System Thermodynamics) and DOE-2.1E programs have developed a third program, EnergyPlus, which combines the potentialities of both. Another research states that EnergyPlus is one of the most used buildings simulation programs in the world. It was developed to estimate heat exchange, lighting levels and energy consumption of buildings, from the physical modeling of the building and its ventilation systems, lighting, heating and cooling [23].

The EnergyPlus operates in accordance with ASHRAE Standards 90.1 [24] and ASHRAE 140 [25]. It can be downloaded for free from the program's website, along with more than two thousand climate archives from around the world. Despite being one of the thermo energy performance computational tools with wide acceptance by researchers, it is still considered an unfriendly tool.

The DesignBuilder program launches as a graphical tool for modeling buildings, which uses the EnergyPlus program for calculating computer simulations. Based on a researcher, the DesignBuilder program facilitates the modeling and configuration of models, an aspect that is more complex on EnergyPlus [26].

It is claimed that the most important to be considered in simulation programs is the accuracy of results and its efficiency, since it is not always possible to reconcile these factors to a reduced complexity of the problems. The author provides a description and analysis of eight different softwares that assess thermal performance and a deeper look into what was mentioned about EnergyPlus [27].

These researchers give a general outline in the Brazilian panorama. It is well-known that many other resources are available in the market, with superior, inferior, and even equivalent performance.

\section{Objective}

The aim of this study is to verify the impact of thermal bridges in residential buildings with reinforced concrete in the eight climatic zones in Brazil, varying the thermal transmittance and the solar absorptance of the walls, thus comparing the effect of thermal bridges in buildings with more and less isolated enclosures and also checking the impact of the color of the building in this context.

\section{Method}

The research was developed in five stages. In the first stage, it was defined the typology to be studied. It was decided to use a building of four floor and it was used the configuration setup as recommended by the RTQ-R (Quality Technical Standard for Energy Efficiency Level in Residential Buildings), observing the characteristics of use and occupation, the density of the internal charge, as shown in Table 1-air conditioning during the night and natural ventilation during the day [9].

After defining the typology, the second stage of the research took place, concerning the modeling and configuration of the building and of the cases to be simulated. For this, the software DesignBuilder Version 3.1.0.036 was used, considering the presence and absence of thermal bridges in the wall structure. For modeling with thermal bridges, due to the limitation of the program used, it was necessary to adapt the model used, calculating equivalent walls as characterized as it follows. The building occupancy was configurated in as shown in Table 2. 
Table 1 Typology and use.

\begin{tabular}{|c|c|c|c|}
\hline Dimension & & $23 \mathrm{~m} \times 8.5 \mathrm{~m}$ & \\
\hline Number of floor & & 4 & \\
\hline Ambience & Activity performed & Heat produced $\left(\mathrm{W} / \mathrm{m}^{2}\right)$ & Heat produced for skin area $=180 \mathrm{~m}^{2}(\mathrm{~W})$ \\
\hline Living room & Sitting or watching TV & 60 & 108 \\
\hline Bedrooms & Sleeping or resting & 45 & 81 \\
\hline Air conditioning system & \multicolumn{3}{|c|}{ COP 3.00 (cooling); COP 2.75 (heating) } \\
\hline
\end{tabular}

Table 2 Building occupancy.

\begin{tabular}{lllll}
\hline \multirow{2}{*}{ Hours } & \multicolumn{3}{c}{ Bedrooms } & Living room \\
\cline { 2 - 5 } & Day of the week & Weekends & Day of the week & Weekends \\
\hline $1 \mathrm{~h} \sim 7 \mathrm{~h}$ & $100 \%$ & $100 \%$ & $0 \%$ & $0 \%$ \\
$8 \mathrm{~h} \sim 9 \mathrm{~h}$ & $0 \%$ & $100 \%$ & $0 \%$ & $0 \%$ \\
$10 \mathrm{~h}$ & $0 \%$ & $50 \%$ & $0 \%$ & $0 \%$ \\
$11 \mathrm{~h}$ & $0 \%$ & $0 \%$ & $25 \%$ \\
$12 \mathrm{~h}$ & $0 \%$ & $0 \%$ & $0 \%$ & $75 \%$ \\
$13 \mathrm{~h}$ & $0 \%$ & $0 \%$ & $25 \%$ & $0 \%$ \\
$14 \mathrm{~h}$ & $0 \%$ & $0 \%$ & $25 \%$ & $75 \%$ \\
$15 \mathrm{~h} \sim 17 \mathrm{~h}$ & $0 \%$ & $0 \%$ & $25 \%$ & $50 \%$ \\
$18 \mathrm{~h}$ & $0 \%$ & $0 \%$ & $100 \%$ & $25 \%$ \\
$19 \mathrm{~h}$ & $0 \%$ & $0 \%$ & $50 \%$ & $25 \%$ \\
$20 \mathrm{~h}$ & $0 \%$ & $50 \%$ & $50 \%$ & $50 \%$ \\
$21 \mathrm{~h}$ & $0 \%$ & $100 \%$ & $0 \%$ & $50 \%$ \\
$22 \mathrm{~h} 24 \mathrm{~h}$ & $50 \%$ & $00 \%$ & & $0 \%$ \\
\hline
\end{tabular}

In the third stage, seeking to optimize the time required for the simulations and changes in the parameters case by case, it was developed an optimization on the simulation, described in Section 2.2.

After the elaboration of the model and the configuration of the cases through the DesignBuilder program, the simulations were started - the fourth stage of the research. The residential building was simulated with different configurations. The changes in each case were: the wall thickness (Tables 3 and 4)- to obtain different thermal transmittances achieved from the calculation of the equivalent wall; and solar absorptance, ranging from a light color to a dark, based on RTQ-R [9]. Unchanged in all cases, the light density and equipment charge density remained, referenced by NBR 16401 [28] and by RTQ-R [9].

A total of 32 configurations were simulated for each climatic context of the eight Brazilian bioclimatic zones, represented by the cities: Curitiba,
Santa Maria, Florianópolis, Brasilia, Vitória da Conquista, Campo Grande and Cuiabá e Manaus.

The fifth and last stage was the analysis and discussion of the results, in order to understand the behavior of the building and the influence of thermal bridges in residential buildings.

\subsection{Definitions of Typology and Use and Occupancy Characteristics}

As previously mentioned, the choice of the typology to be studied was a residential building of four floors, characterized in the following tables. In order to analyze the influence of thermal bridges, for the simulation of the cases without the presence of thermal bridges, a self-supporting ceramic system was chosen and for the case with the presence of thermal bridges, a structural skeleton system of reinforced concrete. In order to represent, in the first case, the most common form of computer modeling, disregarding the structural system, and in the second 
Table 3 Configuration of the cases without thermal bridges.

\begin{tabular}{|c|c|c|c|c|c|}
\hline $\begin{array}{l}\text { Cases without } \\
\text { thermal bridges }\end{array}$ & $\begin{array}{l}\text { Thermal transmittance } \\
\left(\mathrm{W} / \mathrm{m}^{2} \mathrm{~K}\right)\end{array}$ & $\begin{array}{l}\text { Total thickness of the } \\
\text { equivalent wall }(\mathrm{cm})\end{array}$ & Ceramic thickness (m) & $\begin{array}{l}\text { Ceramic density } \\
\left(\mathrm{kg} / \mathrm{m}^{3}\right)\end{array}$ & $\begin{array}{l}\text { Enclosure } \\
\text { absorptance }\end{array}$ \\
\hline Case 01 & \multirow{4}{*}{2.49} & \multirow{4}{*}{11} & \multirow{4}{*}{0.026} & \multirow{4}{*}{457.31} & 0.2 \\
\hline Case 02 & & & & & 0.4 \\
\hline Case 03 & & & & & 0.6 \\
\hline Case 04 & & & & & 0.8 \\
\hline Case 05 & \multirow{4}{*}{2.26} & \multirow{4}{*}{15} & \multirow{4}{*}{0.03} & \multirow{4}{*}{396.34} & 0.2 \\
\hline Case 06 & & & & & 0.4 \\
\hline Case 07 & & & & & 0.6 \\
\hline Case 08 & & & & & 0.8 \\
\hline Case 09 & \multirow{4}{*}{2.08} & \multirow{4}{*}{17} & \multirow{4}{*}{0.04} & \multirow{4}{*}{297.25} & 0.2 \\
\hline Case 10 & & & & & 0.4 \\
\hline Case 11 & & & & & 0.6 \\
\hline Case 12 & & & & & 0.8 \\
\hline Case 13 & \multirow{4}{*}{1.92} & \multirow{4}{*}{20} & \multirow{4}{*}{0.06} & \multirow{4}{*}{198.17} & 0.2 \\
\hline Case 14 & & & & & 0.4 \\
\hline Case 15 & & & & & 0.6 \\
\hline Case 16 & & & & & 0.8 \\
\hline
\end{tabular}

Table 4 Configuration of the cases with thermal bridges.

\begin{tabular}{|c|c|c|c|c|}
\hline $\begin{array}{l}\text { Cases with thermal } \\
\text { bridges }\end{array}$ & $\begin{array}{l}\text { Thermal transmittance } \\
\left(\mathrm{W} / \mathrm{m}^{2} \mathrm{~K}\right)\end{array}$ & $\begin{array}{l}\text { Thickness of the } \\
\text { cluster }(\mathrm{m})\end{array}$ & Ceramic density $\left(\mathrm{kg} / \mathrm{m}^{3}\right)$ & Enclosure absorptance \\
\hline Case 17 & \multirow{4}{*}{2.49} & \multirow{4}{*}{0.011} & \multirow{4}{*}{553.35} & 0.2 \\
\hline Case 18 & & & & 0.4 \\
\hline Case 19 & & & & 0.6 \\
\hline Case 20 & & & & 0.8 \\
\hline Case 21 & \multirow{4}{*}{2.26} & \multirow{4}{*}{0.015} & \multirow{4}{*}{405.79} & 0.2 \\
\hline Case 22 & & & & 0.4 \\
\hline Case 23 & & & & 0.6 \\
\hline Case 24 & & & & 0.8 \\
\hline Case 25 & \multirow{4}{*}{2.08} & \multirow{4}{*}{0.017} & \multirow{4}{*}{358.05} & 0.2 \\
\hline Case 26 & & & & 0.4 \\
\hline Case 27 & & & & 0.6 \\
\hline Case 28 & & & & 0.8 \\
\hline Case 29 & \multirow{4}{*}{1.92} & \multirow{4}{*}{0.020} & \multirow{4}{*}{304.34} & 0.2 \\
\hline Case 30 & & & & 0.4 \\
\hline Case 31 & & & & 0.6 \\
\hline Case 32 & & & & 0.8 \\
\hline
\end{tabular}

case, using a structural system of higher impact on the composition of vertical enclosures, disregarding the structural system, and in the second case, using a structural system of higher impact on the composition of vertical enclosures.

\subsubsection{Definition of Parameters}

In order to assess the impact of the presence of thermal bridges in residential buildings in the Brazilian bioclimatic zones, it was chosen for the computational simulation of the same building with changes of the parameters of the materials present in the enclosures. It was defined different values of U-value and solar absorptance. For the transmittance, it was used the limit value to cooler zones, established by NBR 15575 [6], all other transmittance settings sought results for more isolated buildings. The variation of solar absorptance is also in the values established by the standard. 
As can be seen in Fig. 1, to walls with thermal bridges, there are different $\mathrm{U}$-values for structure and enclosure. The Brazilian standards do not specify the need to ponder these transmittances for simulation, so only the variations in transmittance of the enclosures were used. This situation does not happen on the walls without thermal bridges, as it is considered in this study, a homogeneous wall.

\subsubsection{Equivalent Wall Definition}

To define the configurations of the external wall, it is necessary to create a wall with the same properties of transmittance and thermal capacity of the actual wall, given that the software EnergyPlus understands that enclosures are composed of homogeneous layers. In the real world enclosures, especially of ceramic brick, heterogeneous layers are formed.

In the model where there are not thermal bridges, the exterior walls were set directly using the U-values, resistance and thermal capacity were obtained through the calculation of the walls equivalent. The properties of these materials have been configured according to standard NBR 15220 [5] and their thicknesses were defined based on the same equivalence calculation. To generate the transmittance difference between the cases, the thickness of the ceramic brick was changed so that the wall system had the final desired U-value.

In the models with bridges, there was higher complexity in relation to computer modeling, since the program does not recognize heterogeneous vertical enclosures when using the basic features that it offers. However, it was possible to simulate the effect of the structural system of reinforced concrete and with this, simulate the presence of bridges that occur in this case, when the direction of heat flow is changed by different thermal conductivities present in the envelope. Thus, elements named subsurfaces was used, which allow overlapping elements, in this case, the concrete to the external walls, so as to recreate the effect of a reinforced concrete structure with enclosures in masonry. Because there is an overlap of elements, it was decided to configure the template enclosures of the model based on an equivalence calculation for which, in spite the overlap materials the U-value of the wall system had remained the same and the difference of the materials was evident to the program. The part that represents the masonry of the enclosure appears represented as a subsurface of cluster overlaid on the concrete wall. It was chosen a cluster of low external transmittance, in order to avoid the effects of the accumulation of heat in the external structure of the building.

\subsection{Optimization and Generation of Cases}

To avoid the task of configuring all cases manually, the practical solution found was to implement an algorithm, which produced an input file in idf format - format exported by DesignBuilder - it was possible to generate a total of 32 settings for analysis, with their respective modifications.

\subsubsection{Implementation of the Algorithm}

Given the difficulty in creating cases for the simulation by modifying the properties proposed by the settings of the manual work, the use of algorithms has been the strategy adopted to reduce the working time and to ensure with reliability with the change of the parameters required for simulation. To perform the changes, the Python programming language was adopted, as it has versatility, concepts that are favorable to small implementations and performance in scientific research on a general level [29].

Having knowledge of the location of the information that needs to be changed, it activated the replace method, presented in the standard library of Python programming language [30]. Initialized in the execution, the replace method receives the original material data that need to be modified as parameters, and the values that will be updated, its job is to replace the second parameter (new data) by the original value (original data). In this way, it is possible to update any property that provides a change necessary for analysis in a practical way and in a short amount of time in comparison to manual changes 
(without computer assistance).

For other changes related to the algorithm used, the Eppy library seeks to facilitate the file editing process of the file obtained as output of DesignBuilder containing methods that reduce the implementation time, facilitating the editing process [31].

The computational complexity of the implemented algorithm is $\mathrm{O}(\mathrm{n})$ according to the author, since only a search is performed by the input file regardless of the size of the entry in question [32].

\subsection{Optimization and Simulation Process}

Because of the need to simulate the 32 cases with and without the presence of thermal bridges in the wall composition, for the eight bioclimatic zones, which totaled 256 simulations, the process was optimized.

The first step of this optimization was made by converting the idf Version 7.2 file, exported by DesignBuilder (altered by the algorithm in each case) for EnergyPlus 8.3 Version. With this, the time of the simulations was considerably reduced because of improvements of the software Version 8.3, along with the group in simulation option found in EPLaunch-a graphic support tool EnergyPlus. Through this tool, it was possible to simulate a group of cases to the eight Brazilian bioclimatic zones, simultaneously exploring the best performance of the machine in question, with the use of OpenMP concepts that seeks to take advantage of the best possible performance for a processor with different cores [33].

\section{Analysis of Results}

The process of analysis of the results was developed through comparing buildings with and without the presence of thermal bridges. For these comparisons, it was considered, according to the RTQ-R, the same values for use and occupancy, equipment, lighting and density were used [9].

At both simulated buildings, the value found for the lighting power consumption targeting all cases was $5,487.1 \mathrm{kWh} /$ year and for the equipment the consumption value obtained was 4,198.2 $\mathrm{kWh} /$ year. Although the consumption values presented in lighting and equipment are significant within the building energy consumption, because they have constant values in all simulated cases, these data were not included in the following comparisons presented.

\subsection{Bioclimatic Zones 1 and 2}

The analysis involving the Brazilian Bioclimatic Zones 1 and 2, zones that have the lower temperatures in winter, shows a very similar behavior related to the energy consumption in both cases, in this work represented by Bioclimatic Zone 1 (Fig. 2). In most cases, buildings without the presence of thermal bridges in the wall composition have a lower total power consumption, considering heating and cooling, when compared with buildings that have thermal bridges. Considering the energy spent on heating, the cases without the presence of thermal bridges are more economical. In a more extreme case, there is a difference of $58 \%$ in power consumption between cases with and without bridges for this zone. For the cooling evaluation, the opposite occurs, most of the cases with the presence of thermal bridges have a lower consumption, with a difference of up to $67 \%$ in the most extreme case. This high value is compensated by the large difference in the consumption of heating among all cases.

\subsection{Bioclimatic Zone 3}

The analysis of Bioclimatic Zone 3 shows a distinct behavior, unlike the situations analyzed in Bioclimatic Zones 1 and 2. In most cases, buildings with the presence of thermal bridges in the wall composition have a lower energy consumption, considering heating and cooling, compared to cases without the presence of thermal bridges, except for when solar absorptance presents its lowest value (Fig. 3). To evaluate the consumption with heating, the same pattern discussed in Bioclimatic Zones 1 and 2, where cases without the presence of the bridges consume less power, provided 
Bioclimatic zone 01

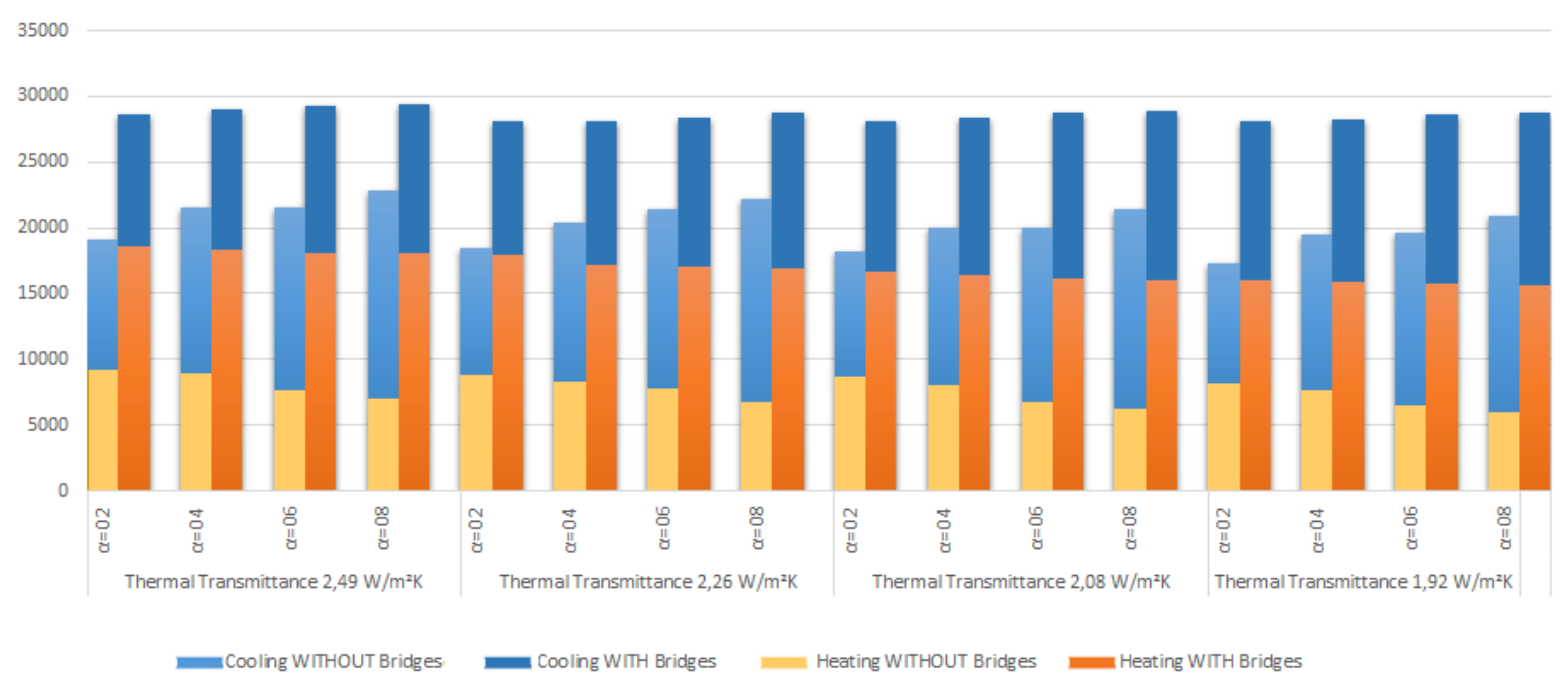

Fig. 2 Bioclimatic Zone 1.

Bioclimatic zone 03

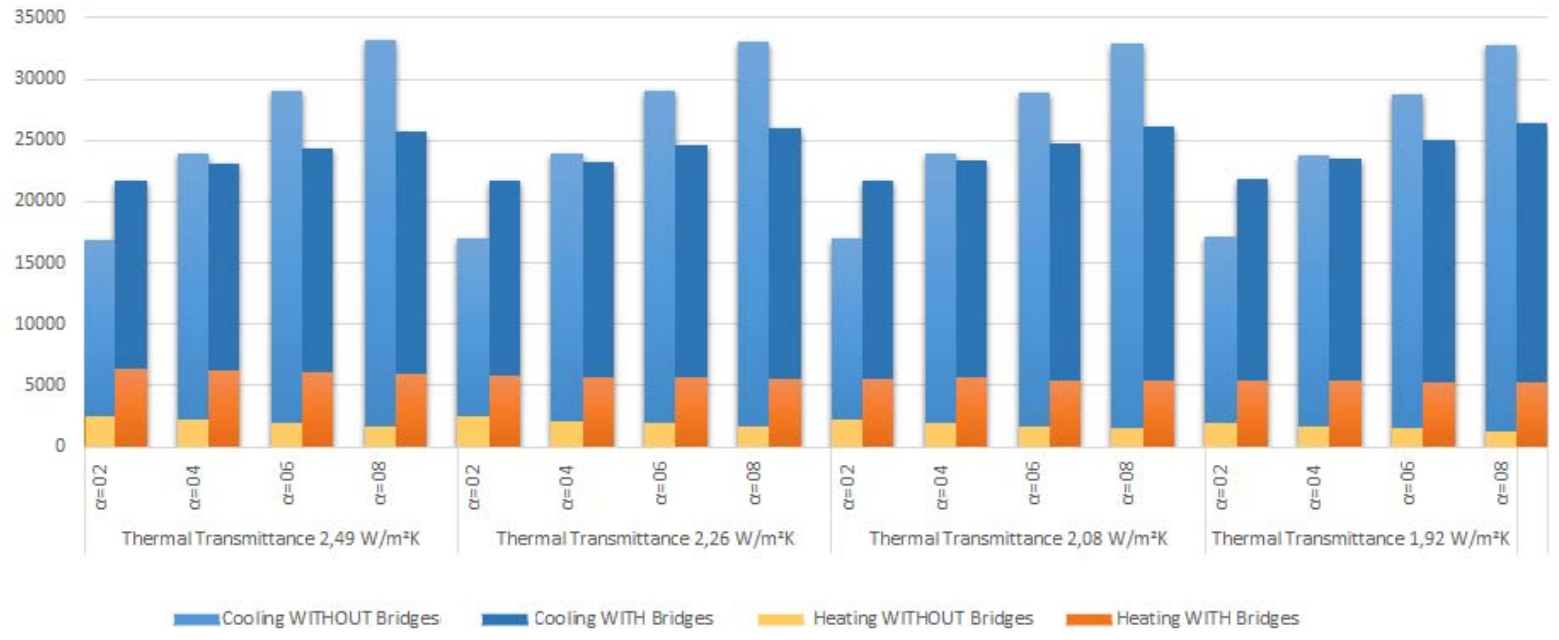

Fig. 3 Bioclimatic Zone 3.

savings of up to $75 \%$ in the most extreme case. Regarding cooling, the cases with the presence of bridges are more economical, with $59 \%$ savings in energy consumption.

Solar absorptance remains an important parameter in power consumption, in all cases with lower absorbance, regardless of insulation level, the energy consumption is lower. In all cases, the average simulated for Zone 3, the simulated buildings with the presence of thermal bridges in the wall composition, show 7\% reduction in energy consumption concerning the case without the presence of thermal bridges in this zone.

\subsection{Bioclimatic Zone 4}

The analysis of Bioclimatic Zone 4 shows a unique behavior. In all cases with the presence of thermal bridges, independently of the value of solar absorptance and isolation, it has lower energy consumption, considering heating and cooling 
compared to cases without the presence of thermal bridges (Fig. 4). For heating, cases with the presence of thermal bridges have a value with little representation in the total energy consumption, as for cooling, cases with the presence of thermal bridges have a lower power consumption, resulting in a difference of up to $49 \%$ of consumption in the most extreme case.

For both cases with the presence of thermal bridges as for cases without the presence of thermal bridges, the absorptance with lower value has a lower power consumption, independently of the configured isolation. At an average of all simulated cases, buildings with the presence of thermal bridges can represent $25 \%$ reduction in energy consumption.

\subsection{Bioclimatic Zones 5 and 6}

As analysis of the Bioclimatic Zones 5 and 6, which shows higher temperatures throughout the year, the observed behavior is similar in both cases, represented in this study by the Bioclimatic Zone 5. In general, considering the energy consumption for heating and cooling, the cases with the presence of thermal bridges in the wall composition have lower power consumption, except in cases where solar absorptance has the lowest values (Fig. 5). The consumption for heating in the case without the presence of thermal bridges is smaller when compared to cases with the presence of the bridges. In both zones, the energy consumption the evaluation of the heating did not show significant values considering the total energy consumed in the building. Since the energy consumption for cooling is less than in the cases with the presence of thermal bridges, compared with cases without bridges, with a difference of up to $59 \%$ of energy consumption in the case with the most extreme difference.

For all levels of insulation, the lowest solar absorptance has a lower power consumption. Analyzing only the Bioclimatic Zone 5, in all simulated cases, the presence of thermal bridges had a reduction of $21 \%$ in total energy consumption.

\subsection{Bioclimatic Zones 7 and 8}

For the analysis of Bioclimatic Zones 7 and 8-Brazilian bioclimatic zones that have high temperatures throughout the year, it was possible to identify a pattern for similar power consumption between the cases, represented in this item by Bioclimatic Zone 7 (Fig. 6). The energy consumption for heating and cooling in cases with the presence of thermal bridges in the wall composition showed lower values,

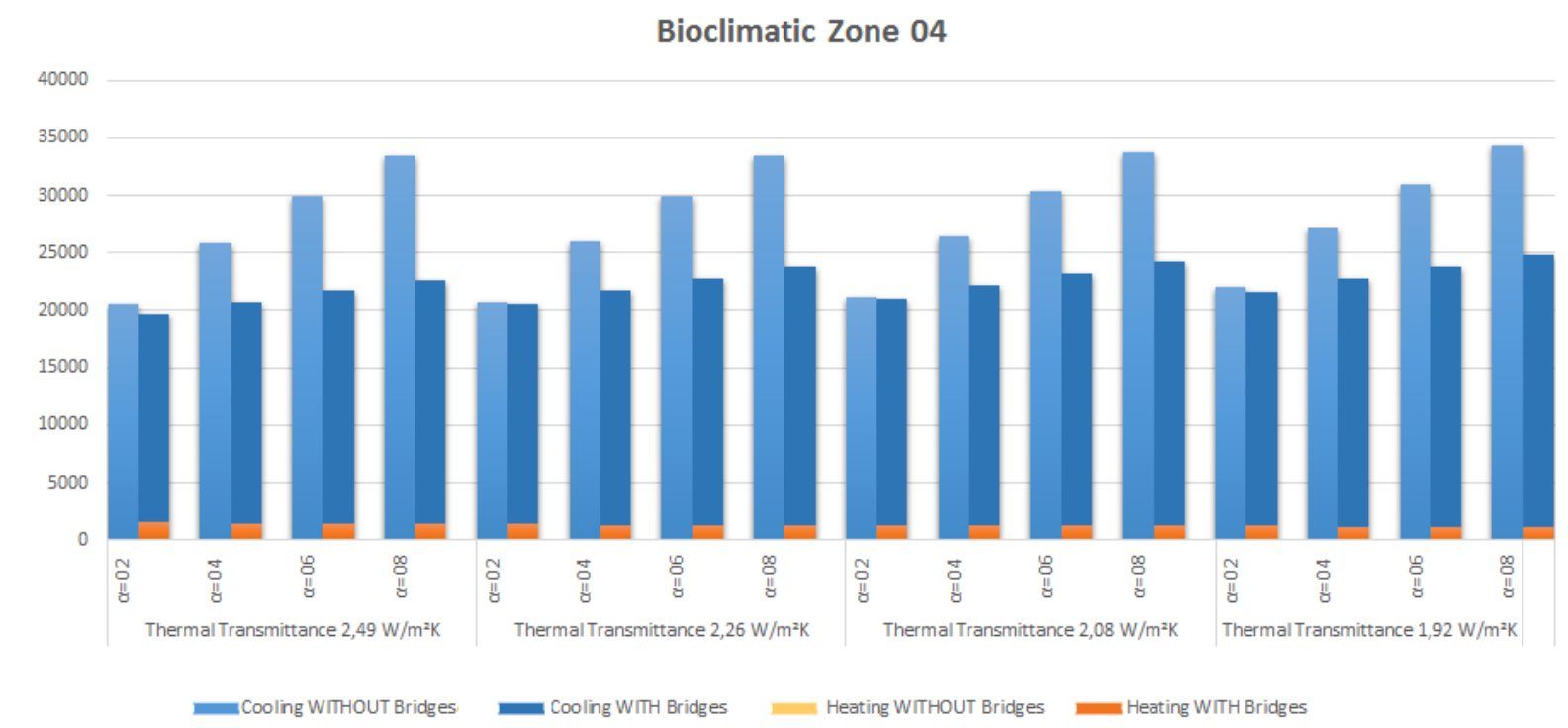

Fig. 4 Bioclimatic Zone 4. 
Bioclimatic zone 05

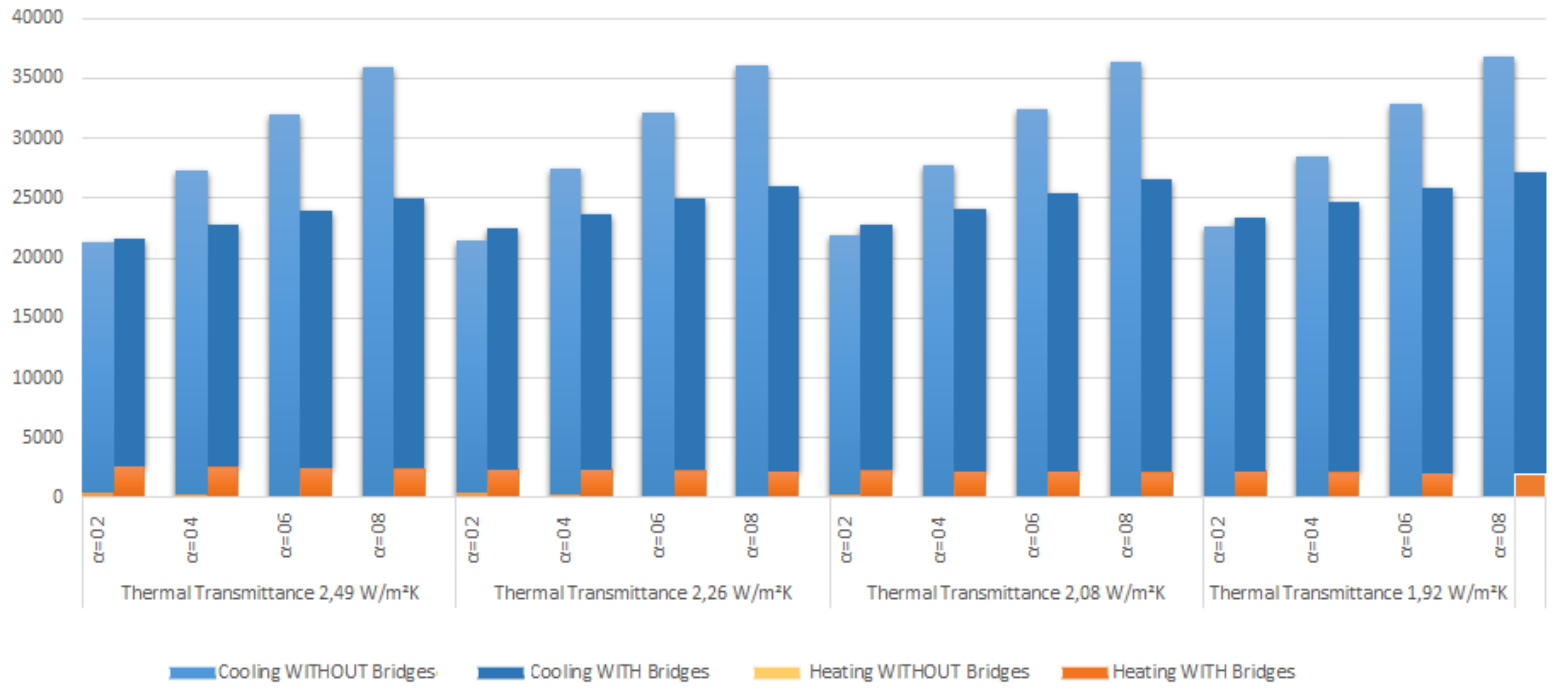

Fig. 5 Bioclimatic Zone 5.

Bioclimatic zone 07

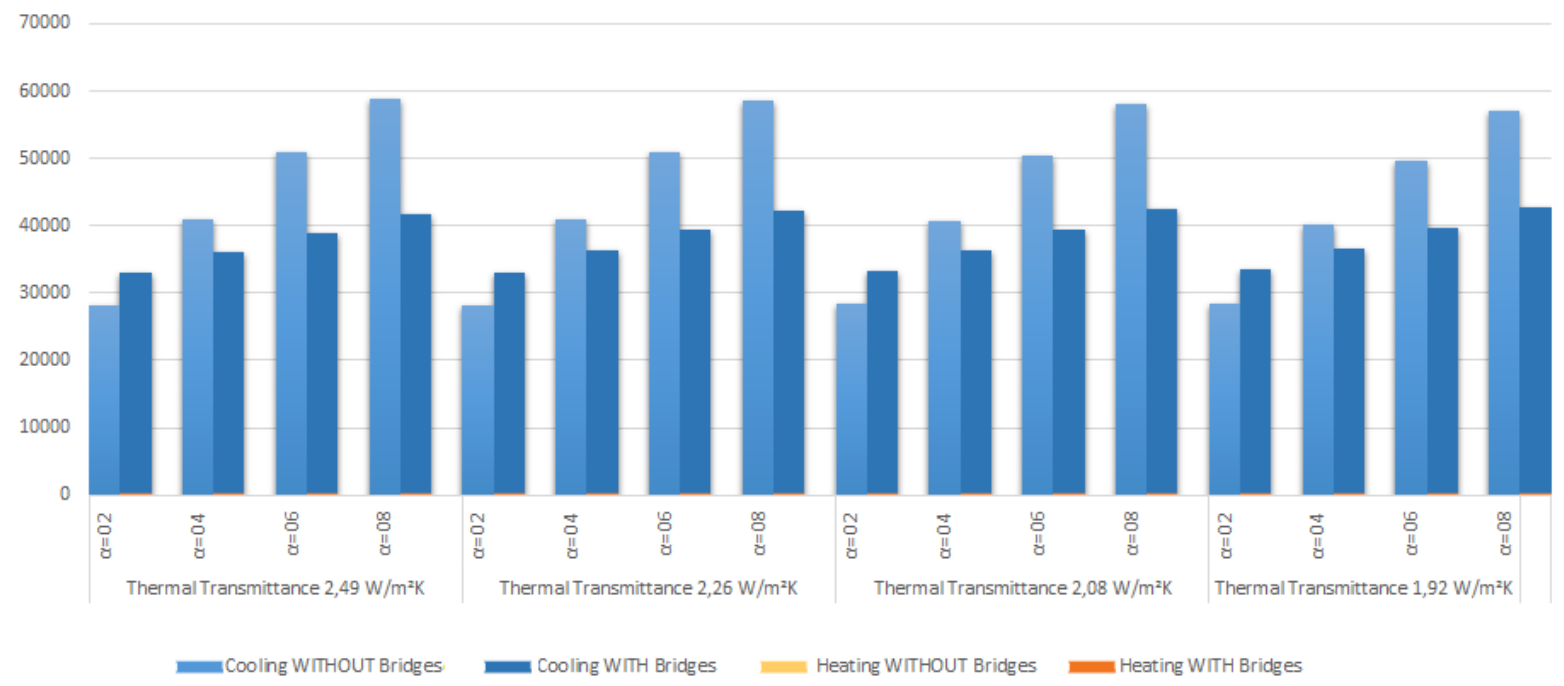

Fig. 6 Bioclimatic Zone 7.

compared to the case without the presence of thermal bridges, except in cases with lower solar absorptance (as seen previously in Bioclimatic Areas 3, 5 and 6). The consumption of energy for heating in Bioclimatic Zone 7 was practically zero, as it can be seen in the chart below. As for Bioclimatic Zone 8, the heating consumption does not show values, for both a greater cooling consumption in most cases without the presence of thermal bridges, reaching a difference of up to $42 \%$ in the extreme case.
As in all other zones, the building with the lowest solar absorptance is the lowest energy consumer. Considering the average of all simulated cases for Zone 7, buildings with the presence of thermal bridges can represent a reduction of $17 \%$ consumption.

\subsection{Percentage of Results for the Eight Brazilian} Bioclimatic Zones

Concluding the analysis, this item presents a general percentage relation of the information discussed above. 
4.6.1 Bioclimatic Zones 1 and 2

According to Fig. 7, it is possible to notice the percentage behavior of Bioclimatic Zones 1 and 2 discussed in Section 4.1.

4.6.2 Bioclimatic Zone 3

According to Fig. 8, it is possible to notice the percentage behavior of Bioclimatic Zone 3 discussed in Section 4.2.

\subsubsection{Bioclimatic Zone 4}

According to Fig. 9, it is possible to notice the percentage behavior of Bioclimatic Zone 4 discussed in Section 4.3.

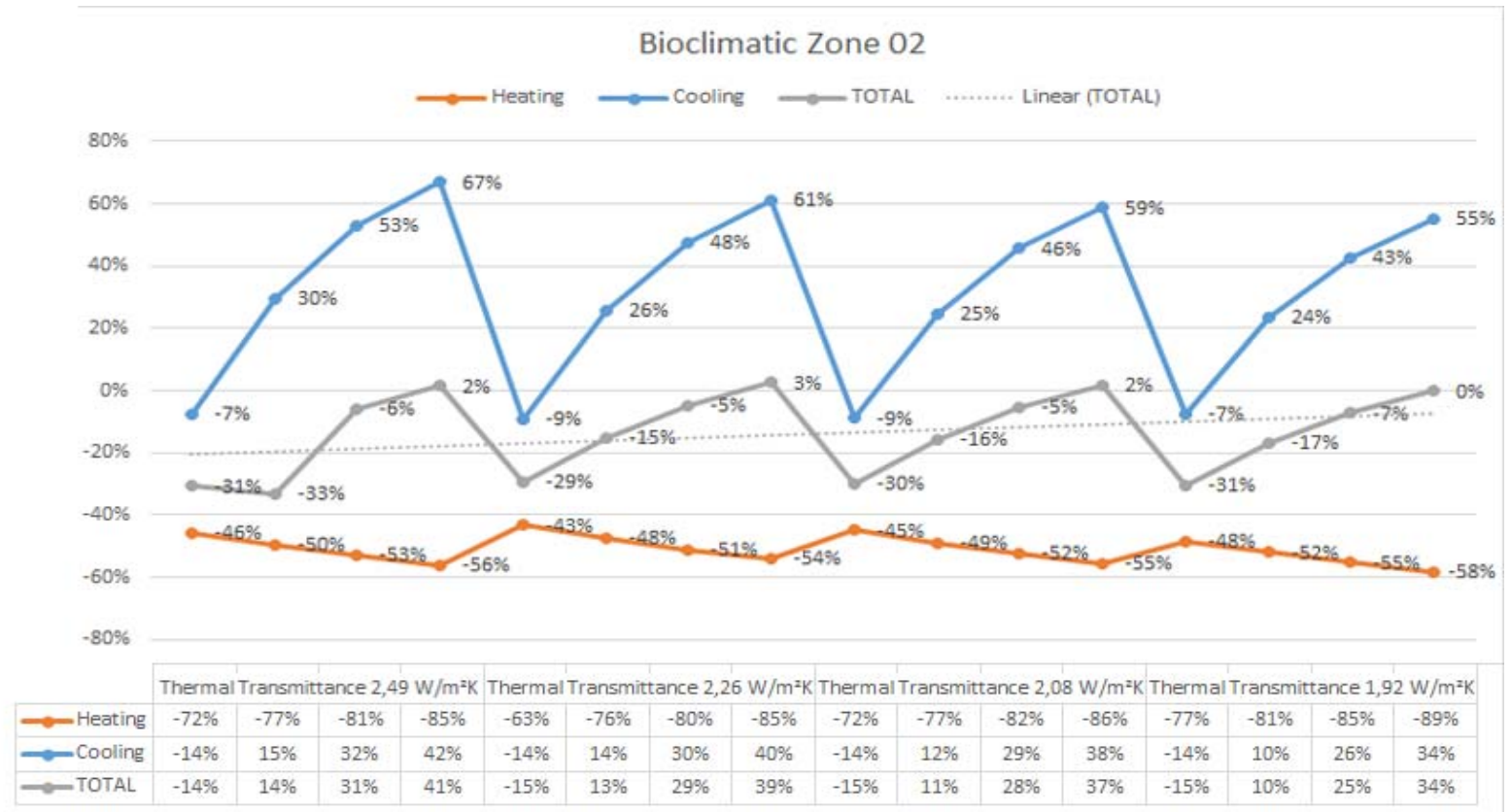

Fig. 7 Results in percentage to Bioclimatic Zone 2.

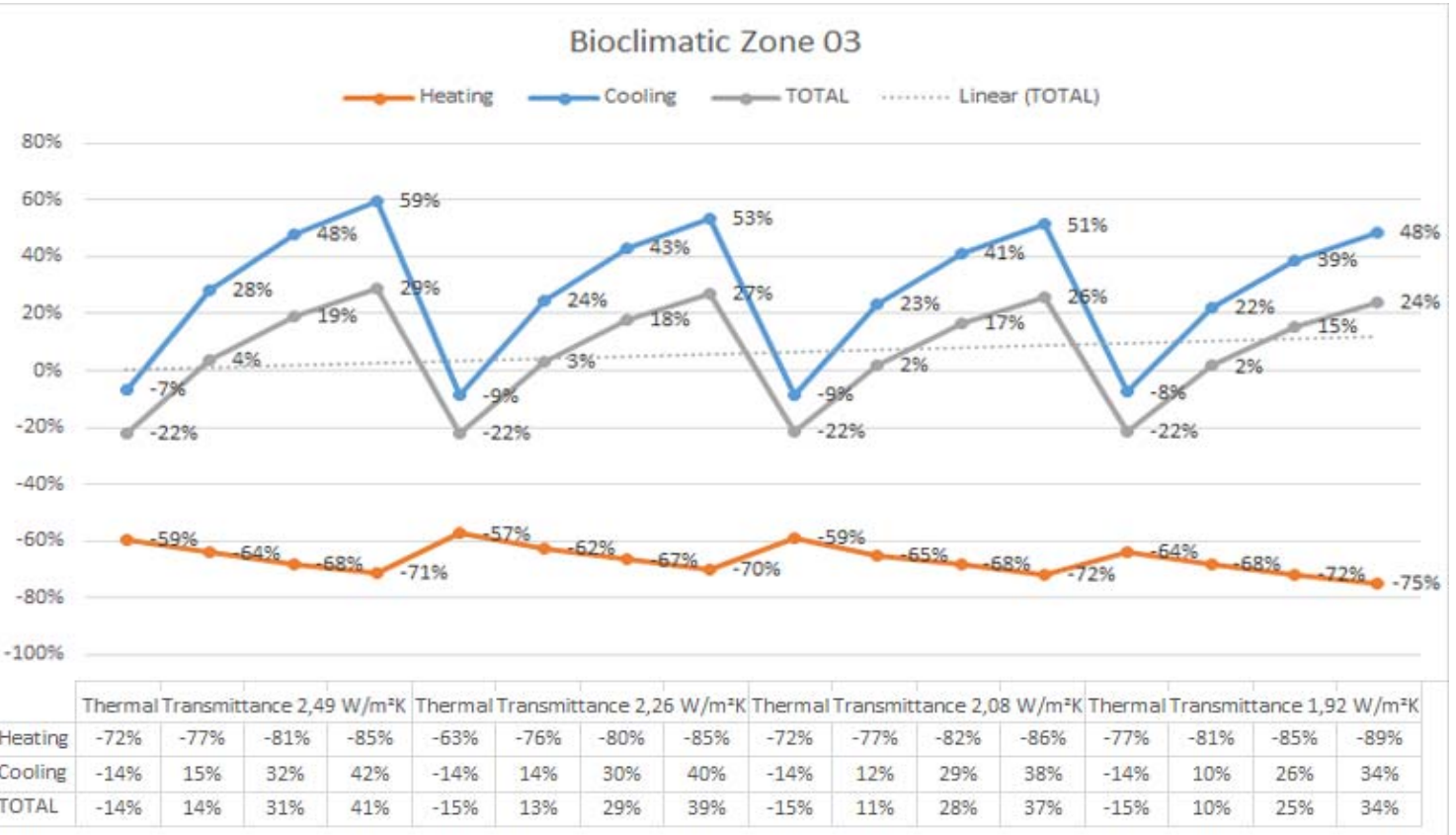

Fig. 8 Results in percentage to Bioclimatic Zone 3. 


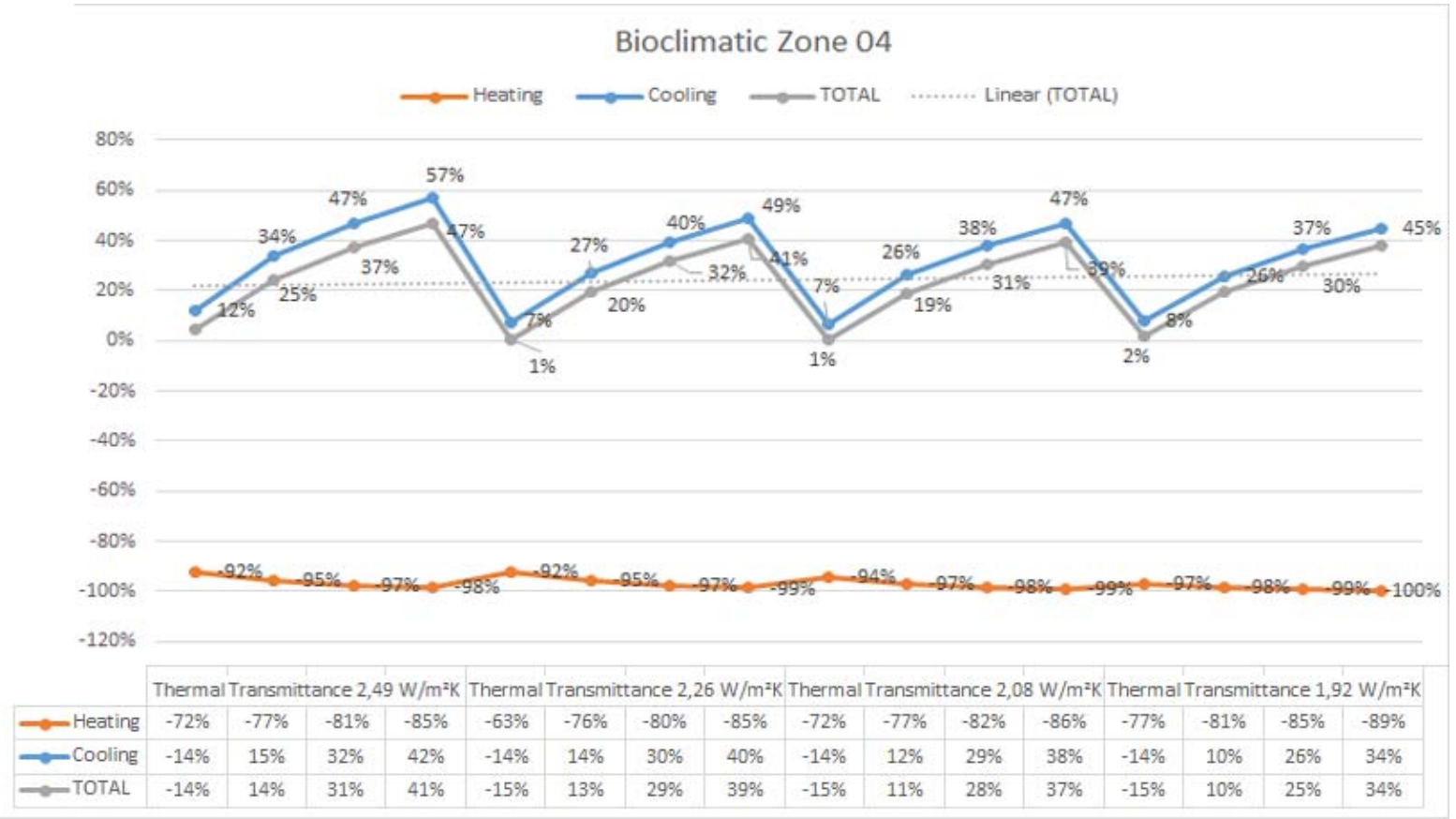

Fig. 9 Results in percentage to Bioclimatic Zone 4.

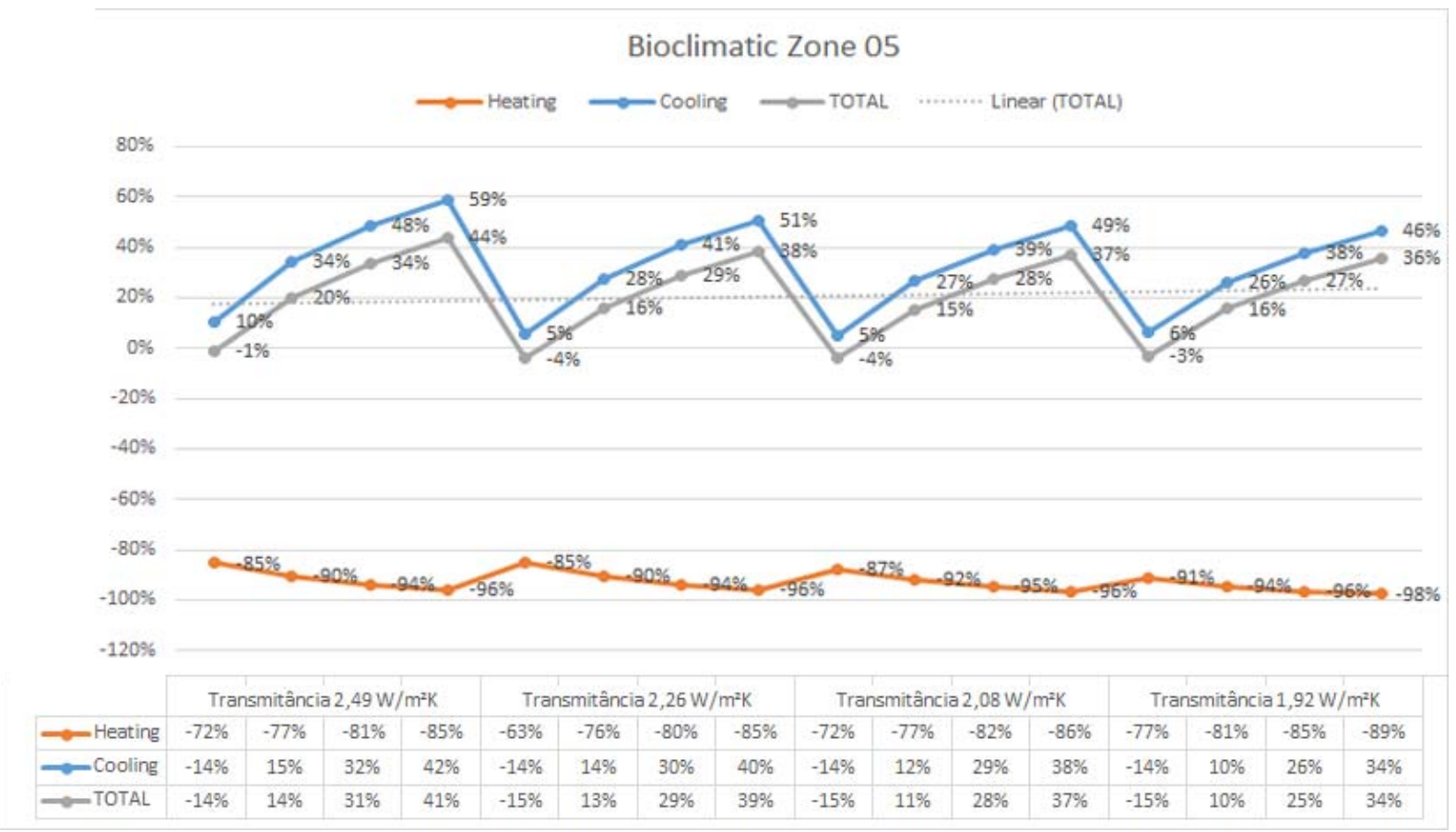

Fig. 10 Results in percentage to Bioclimatic Zone 5.

\subsubsection{Bioclimatic Zones 5 and 6}

According to Fig. 10, it is possible to notice the percentage behavior of Bioclimatic Zones 5 and 6 discussed in Section 4.4.

\subsubsection{Bioclimatic zones 7 and 8}

According to Fig. 11, it is possible to notice the percentage behavior of Bioclimatic Zones 7 and 8 discussed in Section 4.5. 


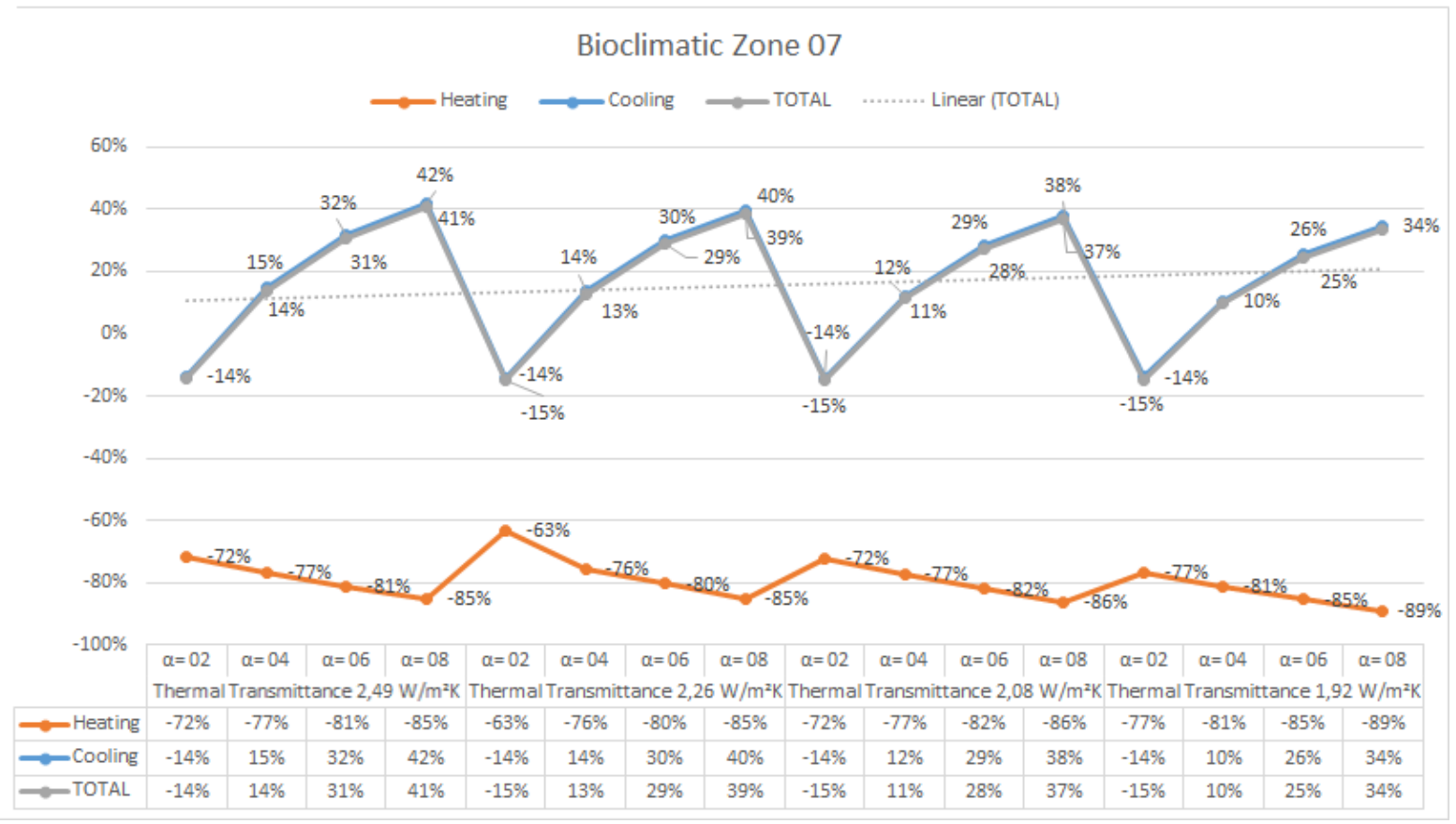

Fig. 11: Results in percentage to Bioclimatic Zone 7.

\section{Conclusions}

Considering the results presented, the aim of this study was to achieve in verifying the impact of thermal bridges in residential buildings. Comparing the effect of thermal bridges in buildings with more or less isolated enclosures and different absorptances, it was found that the color is the primary influence in the change of power consumption.

The elaboration of this study has contributed in highlighting the importance of the discussion involving the presence of thermal bridges in the composition of the wall structure. According to the results presented for initial Brazilian bioclimatic zones (1 and 2)-zones that have cold weather in winter, it is possible to observe an oversizing on energy consumption, since the presence of thermal bridges in residential buildings tested in these regions does not provide advantages on energy consumption when compared to buildings without the presence of thermal bridges. Considering all the other Brazilian bioclimatic zones, with the inclusion of thermal bridges in vertical enclosures, it is possible to observe an undersizing on energy consumption, as thermal bridges collaborate to reduce energy consumption in these zones.

\subsection{Generated Discussion}

Facing the problems of thermal bridges and the non-inclusion in the modeling, we bring the discussion of the structural system inclusion in computational modeling. This final assessment can be understood based on two possibilities: including the structural system directly in modeling, or considering the structure in the equivalent wall transmittance calculation.

Although the RTQ-R [9] recommends when it comes to heterogeneous enclosures weighting to ponder upon the calculation of U-value, there is no discussion on the structure in relation to the simulation. During the simulation process is not clear if the thermal transmittance of the walls should be used only for the enclosure or if the U-value is a result from the ponderation between closing and structure.

From the simulation point of view, modelling the structural system is not common, however, the results showed a difference in consumption when the same 
building is simulated considering its structure. Here comes into play the discussion on the need of adding the elements that represent this structure, as in the present work: subsurfaces; or calculating a transmittance to consider closure and structure. The results show that working without the modeling of the structure in the vertical enclosures, can generate considerable differences in energy consumption.

\section{References}

[1] Ministry of Mines and Energy. 2014. National Energy Balance. Brazil. Accessed June 4, 2015. https://ben.epe.gov.br/.

[2] Lamberts, R. 2014. Energy Efficiency in Architecture. 3rd ed. Rio de Janeiro: Eletrobras/Procel.

[3] Brasil. 2001. Law 10295, Octuber 17, 2001. Accessed June 4, 2015. http://www.inmetro.gov.br/qualidade/ pdf/lei10295.pdf.

[4] Brasil. 2001. Decree 4059, December 19, 2001. Accessed June 4, 2015. http://www.mme.gov.br/ministerio/ legislacao/decretos/Decreto\%20n\%204.059-2001.html.

[5] Brazilian Association of Technical Standards. 2005. NBR 15220-3: Thermal Performance of Building - Part 3: Brazilian Bioclimatic Zoning and Constructive Guidelines for Houses of Social Interest. Brazil.

[6] Brazilian Association of Technical Standards. 2008. NBR 15575: Performance of Buildings for More than Five Floors: Part 1: General Requirements. Rio de Janeiro, Brazil.

[7] Melo, A. P. 2009. Basic Course of EnergyPlus. Accessed November 10, 2015. http://www.labeee.ufsc.br/sites/ default/files/disciplinas/ECV4202_Apostila_EnergyPlus_ 0 .pdf.

[8] Oliveira, L. 2012. "Evaluation of the Limits of the Thermal Proprieties of Opaque Enclosure by the NBR 15229-3 for Social Housing of Interest, for the Bioclimatic Zone 2.” Master dissertation, Federal University of Pelotas, Brazil.

[9] INMETRO (National Institute of Meteorology, Standardization and Industrial Quality). 2012. RTQ-R-Technical Regulation of Quality for the Level of Energy Efficiency of Residential Buildings. Rio de Janeiro: INMETRO.

[10] ISO (International Organization for Standardization). 2007. ISO 14683: Thermal Bridges in Building Construction-Linear Thermal Transmittance -Simplified Methods and Default Values. Switzerland: ISO.

[11] ISO. 2007. ISO 10211: Thermal Bridges in Building
Construction. Heat Flows and Surface Temperatures. Detailed Calculations. Switzerland: ISO.

[12] Argentine Institute of Standardization. 1996. IRAM 11605: Building Thermal Conditioning. Habitability Condition's in Building. Maximum Values of Thermal Transmittance in Opaque Enclosures. Argentina: Argentine Institute of Standardization.

[13] Argentine Institute of Standardization. 1996. IRAM 11603: Building Thermal Conditioning. Argentina: Argentine Institute of Standardization.

[14] DIN (Deutsches Institut für Nörmung). 2001. DIN 4108-Wärmeschutz und Energie-Einsparung in Gebäuden. Teil 3: Klimabedingter Feuchteschutz, Anforderungen, Berechnungsverfahren und Hinweise für Planung und Ausführung. Germany: DIN..

[15] Portugal. 2006. Regulation of Thermal Performance Characteristics of Buildings (RCCTE). Law 80/2006. Portugal.

[16] Pessoa, J. H. M. 2011. "Analysis of the Influence of Thermal Bridges in Residential Buildings.” Masters dissertation, New Lisbon University.

[17] Gioielli, B., Almeida, A., Cunha, E., and Ferrugem, A. 2014. "Study of Thermal Bridges Effect of Reinforced Concrete Structures in the Energy Performance of Hotel Building for 4 Brazilian Bioclimatic Zones.” In Proceedings of the XV National Meet of Technology on the Constructed Ambience. Alagoas, 1-10.

[18] Evans, J. M., and De Schiller, S. 2010. "Verification of Thermal Bridges Rules to Define Acceptable Solutions." Advances in Renewable Energy and Environment 14: 51-8.

[19] Argentine Institute of Standardization. 2002. IRAM 11549. Thermal Insulation of Buildings. Argentina: Argentine Institute of Standardization.

[20] Haupt, W. 2008. Skript Feuchsteschutz (Reference in Humidity Protection). Kassel: Kassel Universität. (in German)

[21] Kiessel, K., and Sedlbauer, K. 2001. "Neue Erkenntnisse zur Beurteilung von Schimmelpilzen und Stand der Normenbearbeitung (New Findings for the Evaluation of Molds and the State of Standards Processing).” Presented at Weimarer Bauphysiktage, Weimar. (in German)

[22] Hensen, J. L. M., and Lamberts, R. 2011. Building Performance Simulation for Design and Operation. Abingdon: Spon Press.

[23] Pereira, C., and Ghisi, E. 2015. "Calibration of a Computational Model of a Residence Located in Florianópolis.” In Proceedings of the XIII National Meeting and IX Latin American of Confort in the Construed Ambience.

[24] American Society of Heating, Refrigerating and Air 
Conditioning Engineers. 2007. ASHRAE 90.1. 2007. Energy Standard for Buildings Except Low-Rise Residential Buildings. Atlanta: American Society of Heating, Refrigerating and Air Conditioning Engineers.

[25] American Society of Heating, Refrigerating and Air Conditioning Engineers. 2001. ASHRAE 140. Standard Method od Test for the Evaluation of Building Energy Analysis Computer Programs (ANSI approved). Atlanta: American Society of Heating, Refrigerating and Air Conditioning Engineers.

[26] Costa, M. F. 2013. "DesignBuilder Application to the Evaluation of Heating and Cooling Solutions for Buildings of Different Portuguese Regions.” Master dissertation, Porto University.

[27] Menezes, M. S. 2006. "Thermal Evaluation of the Social Housing in Passo Fundo.” Master dissertation, University of Passo Fundo.

[28] Brazilian Association of Technical Standards. 2008. NBR
16401-Central and Unitary Air Conditioning Systems. Brazil: Brazilian Association of Technical Standards.

[29] Coelho, F. C. 2016. Scientific Computing with Python. Asseced October 10, 2015. https://ccpcode.googlecode. com/hg/Text_src/_build/latex/LivroPython.pdf.

[30] Przywóski, J. 2015. Replace Method Documentation. Assessed October 15, 2015. https://python-reference.read thedocs.prg/en/latest/docs/str/replace.html.

[31] Santosh, P. Eppy 0.5.1 Documentation. Acessed November 10, 2015. http://pythonhosted.org/eppy/.

[32] Cormen, T. H., Leiserson, C. E., Rivest, R. L., and Stein, C. 2001. Introduction to Algorithms. 2nd ed. New York: MIT Press \& McGraw-Hill.

[33] Chandra, J., Simon, B., Ravi, D., and Chandran, P. 2009. "Parallelizing SystemC Kernel for Fast Hardware Simulation on SMP Machines.” In Proceedings of the 23rd Workshop on Principles of Advanced and Distributed Simulation. 